\title{
Perrone-Moisés e a escritura: FIDELIDADES E NEOLOGISMOS
}

PerRone-Moisés AND WRITING:

FIDELITY AND NEOLOGISM

\section{Paulo Procopio Ferraz}

ORCID 0000-0002-6166-1510

Universidade de São Paulo, São Paulo, SP, Brasil

\section{Resumo:}

As relações entre Leyla Perrone-Moisés e Roland Barthes passam por uma questão que reaparece constantemente nos escritos da autora: a fidelidade. $\mathrm{O}$ tema da fidelidade atinge, ao mesmo tempo, a crítica literária e a tradução, duas atividades praticadas por Perrone-Moisés. Ele está ligado a dois temas importantes nos textos barthesianos: a escritura e o neologismo. A escritura, além de ser, ela mesma, resultado de um processo de neologismo, é, por definição, produtora de novos sentidos. Para traduzir o termo francês, écriture, Perrone-Moisés propóe uma distinção entre "escritura" (o texto literário) e "escrita" (a escrita instrumental, próxima do texto intelectual). Essa distinção opera através de um tipo de neologismo particular, batizado de "paleologismo", curiosa figura que se situa na fronteira entre fidelidade e infidelidade.

Palavras-chave: Écriture, escrita, escritura, neologismo, paleologismo.

\section{Abstract:}

The relationship between Leyla PerroneMoisés and Roland Barthes involves a subject that frequently appears in her texts: fidelity. This subject was also present in two activities that were practiced by Leyla Perrone-Moisés: literary criticism and translation. It is also connected to two important themes in the texts written by Barthes: writing and neologism. Besides being a neologism itself, writing is, by definition, something that produces new meanings. To translate the French word, écriture, Perrone-Moisés uses a distinction between "escritura" (the litterary text) and "escrita" (the instrumental text similar to the text produced by intellectuals). This

\section{Résumé:}

Les rapports entre Leyla Perrone-Moisés et Roland Barthes sont liés à une question qui apparaît fréquemment dans les écrits de l'auteure : la fidélité. Le thème de la fidélité concerne, en même temps, la critique littéraire et la traduction, deux activités pratiquées par Perrone-Moisés. Il est lié à deux thèmes importants des textes barthesiens: l'écriture et le néologisme. L'écriture (mot qui est lui-même un néologisme) est une activité qui produit nécessairement des sens nouveaux. Dans sa traduction du mot français, PerroneMoisés propose une distinction entre " escritura " (l'écriture de l'écrivain) et " escrita» (l'écriture instrumental, proche 
distinction is the product of a special kind of neologism, called "paleologism", which is located precisely in the frontier that separates fidelity from infidelity.

Keywords: Writing, neologism, paleologism. de celle de l'intellectuel). Cette distinction est possible à partir d'un type particulier de néologisme, appelé "paléologisme ", qui se situe sur la frontière qui sépare la fidélité de l'infidélité.

Mots-clés: Écriture, néologisme, paléologisme.

\section{Fidelidade e infidelidade}

Em 1970, Leyla Perrone-Moisés publica um artigo intitulado Roland Barthes, o infiel (2012). Perrone-Moisés relata que, ao tomar conhecimento do texto da autora, Barthes se surpreendeu com a utilizaçáo do adjetivo "infiel". Exclamou: "Mas sou muito fiel a minhas obsessóes!". Logo depois, corrigiu-se: "Digamos que as minhas obsessôes me são extremamente fiéis" (PERRONE-MOISÉS, 2012c, p. 128). Ela já havia escrito que a obra de Barthes possuía "algumas linhas de força que permanecem constantes sob variação” (PERRONE-MOISÉS, 2012, p. 24). O que podemos concluir é que a fidelidade aparece, em Barthes, como a caução da infidelidade: ela é a condição necessária para pensar seus constantes movimentos. Talvez estejamos diante de uma ambiguidade: de fato, é possível falar em infidelidade sem, imediatamente, evocar seu contrário? O que poderia significar, para um leitor, uma fidelidade ao texto? Inversamente, em que condiçóes poderíamos afirmar que traímos um autor na medida em que o lemos? Afinal, até que ponto é possível permanecer fiel às suas próprias obsessōes sem traí-las? Para oferecer alguns elementos de resposta a essas perguntas, refletiremos sobre duas atividades extensamente praticadas pela autora e que sempre implicaram, de um modo ou de outro, uma interrogação sobre a fidelidade: a crítica e a tradução.

Perrone-Moisés afirma que o objetivo da crítica é "a explicação e a avaliação de outros textos" (2005, p. 56). Para cumprir essas duas funções, é preciso manter um tipo de fidelidade ao passado. Ao explicar uma obra, somos obrigados a entendê-la como um objeto acabado: o crítico não tem direito nem de completá-la, nem de suprimir trechos que lhe desagradam. Para avaliá-la, é necessário compará-la a obras antigas, vistas como modelos estéticos que servem de referência para os textos atuais. Ora, em sua tese de livre-docência, defendida em 1975 e publicada três anos depois, PerroneMoisés argumenta que a noçâo barthesiana de "escritura" póe em questão as duas funçóes da crítica. 
A escritura é uma ideia que não possui uma definição precisa: Barthes modificava incessantemente seus sentidos, operando constantes deslocamentos (ver PERRONE-MOISÉS, 2012b) ${ }^{1}$. Por ora, examinaremos apenas as razōes pelas quais crítica e escritura aparecem como dois princípios contraditórios. A escritura é entendida como uma atividade infinita: situa-se no presente porque está em processo de fabricação contínua. A rigor, ela não quer dizer nada: é um movimento sem destino que não se preocupa em exprimir um sentido inequívoco. Desse modo, a crítica náo pode exercer sobre ela sua atividade de esclarecimento, pois ela não é clara nem obscura: não é possível iluminála, já que não se apresenta ao exame do olho, mas antes ao movimento da mão. A única resposta à escritura é, desse modo, a própria escritura, ou seja, a continuação do ato que a produz. Além disso, a escritura não faz referência a obras passadas, o que impede a avaliação do texto que ela produz. Quando dialoga com outros textos, é para entendê-los como processos presentes: ao invés de vê-los como um objeto acabado, desenvolve-os para mantê-los sempre vivos e atuais. Náo se refere a eles como modelos, mas como modos de alimentar seu próprio movimento. Recusa, assim, toda avaliaçáo porque desconfia de todos os juízos de valor baseados em cânones estabelecidos.

Em que condiçóes, então, podemos ainda praticar textos críticos? Para responder a essa questão, Perrone-Moisés escreve sobre três autores considerados como críticos-escritores: Maurice Blanchot, Michel Butor e Roland Barthes. Trata-se de processos “ambíguos e ambivalentes" (PERRONE-MOISÉS, 2005, p. 96), ou seja, que reúnem dois tipos de escrita que deveriam, a princípio, ser inconciliáveis. Nos três casos, há uma forma de fidelidade na inovação, o que significa que eles conseguem, ao mesmo tempo, falar sobre os outros textos e produzir uma escritura original. Por exemplo, para Butor, "a única maneira de ser fiel a um texto antigo é torná-lo presente, é lê-lo com a perspectiva de hoje, primeiramente porque a pretensão de recuperar a visão de uma época passada é veleidade e, em segundo lugar, porque ler é inventar" (p. 131).

Em 2000, a questão da fidelidade ainda aparecia como uma interrogação central para Perrone-Moisés. Ela faz o balanço do colóquio realizado em Yale sobre a obra de Barthes do seguinte modo:

Foi ponto pacífico, no final, que se deve resistir à canonização de Barthes, cujos textos já fazem parte dos currículos dos liceus franceses; que ser excessivamente fiel a Barthes seria traí-lo. O que me parece difícil é estabelecer o juste milieu entre a leitura fiel de seus textos [...] e a leitura livre e infiel desses mesmos textos. Nos dois extremos, encontra-se o perigo da imagem: canônica, num extremo, ou "qualquer coisa", no outro (PERRONE-MOISÉS, 2012d, p. 136).

1 Ver PROCOPIO FERRAZ, 2018. 
A dificuldade descrita aqui mostra que as questôes colocadas em sua tese de livre-docência ainda eram atuais no ano 2000. Se alguns dos presentes podiam ser considerados como críticos-escritores (como, por exemplo, Susan Sontag e Michel Déguy), a verdade é que a prática da escritura, que, como veremos, adquiriu um prestígio que não possuía antes, não havia, apesar disso, sido generalizada, contrariamente ao que as tendências de 1975 deixavam entrever. Isso quer dizer que muitos dos leitores de Barthes continuavam a manejar uma linguagem que explicava os textos barthesianos e avaliava sua pertinência. Daí o risco de "canonizar" sua imagem, isto é, de paralisar seus textos para transformá-los em uma obra acabada. O excesso de fidelidade da crítica extermina tudo o que há de vivo no texto que lê, pois anula sua produtividade. A infidelidade aparece como igualmente perigosa: ao liberar-se das exigências da crítica tradicional, transforma o texto barthesiano em mero pretexto, fazendo com que a crítica desconheça o texto que lê.

Esse problema, no caso de Leyla Perrone-Moisés, coloca-se duas vezes. Afinal, além de ser leitora de Barthes, ela é sua principal tradutora no Brasil. Talvez não haja atividade na qual a questão da fidelidade se faça mais presente do que na tradução. Frequentemente, o tradutor busca conformar-se às intençóes do autor. A cada frase, ele se pergunta: estou veiculando fielmente aquilo que foi escrito? Será que meu leitor pode, a partir deste texto que estou produzindo, apreender o pensamento que está na obra original? É assim que o significado passa a adquirir uma importância excessiva com relação ao significante. Trata-se da concepção, presente já nos clássicos, de que se deve traduzir ideias, e não palavras (São Jerônimo apud OUSTINOFF, 2018, locais 317-319 da edição kindle). Entre a res e a verba de Quintiliano (BARTHES, 2002a, p. 563) não podemos hesitar: é preciso, na medida do possível, transmitir um pensamento, e não sua expressão.

Para que essa transposição de sentidos possa existir, é preciso fundar-se sobre uma determinada ideia de "obra", entendida como a expressão mais acabada do pensamento de um autor. Todos os textos que dela derivam ficam, desse modo, submetidos a uma rígida hierarquia. Haveria, por um lado, um original, que transmitiria perfeitamente o pensamento do autor, e, por outro, suas versóes, mais ou menos próximas desse pensamento. Todas as variaçôes, comentários ou traduçóes devem medir-se com relação a esse original: sua qualidade será determinada a partir da proximidade dele, ou, para usar um vocábulo que nos é familiar, ela será avaliada por seu grau de fidelidade. A tradução será, então, necessariamente uma forma de degradação, que exprimirá o pensamento do autor de maneira imperfeita; espécie de mal menor, ela deve ser consultada apenas quando náo se tem acesso ao texto na língua em que ele foi escrito. 
No entanto, sabemos que Barthes opôs a ideia de “Texto" à noção de "obra". Para ele, a obra é uma apropriaçáo indevida do texto pelo autor. Ao vê-la como depositária de uma determinada intencionalidade, colocamos a obra na direta dependência do autor, que passa, entâo, a ter autoridade sobre ela. Autor e obra inventam-se reciprocamente, pois só podem existir a partir de uma relação hierárquica: "o autor é visto como o pai e o proprietário de sua obra; a ciência literária ensina a respeitar o manuscrito e as intençóes declaradas do autor" (BARTHES, 2002b, p. 913)2. O Texto, por outro lado, náo se preocupa com nenhuma autoridade paterna: contrariamente à obra, ele não possui um sentido original a ser preservado. Ele é uma produtividade, o que quer dizer que seus sentidos se alteram com o passar do tempo (p. 913). Traduzir o Texto barthesiano a partir de um respeito a um significado préestabelecido seria, então, trair profundamente as intençóes do próprio autor. Assim, só poderíamos reconstituir o sentido principal da obra de Barthes a partir do mais completo desrespeito às noçóes que ele desenvolveu.

\section{Escrita e escritura}

Para entender a questão da fidelidade e da infidelidade nas relações entre Leyla Perrone-Moisés e Barthes, estudaremos um tema que, como mostraremos a seguir, está relacionado à crítica, à escritura e à tradução: a neologia. Uma das características mais conhecidas dos textos de Barthes é sua tendência ao neologismo. A fabricação de uma palavra é um gesto que, tradicionalmente, pede uma explicação. Em geral, a neologia só nos é permitida quando sentimos que nenhuma das palavras disponíveis corresponde exatamente ao significado que procuramos veicular. Por exemplo, o termo "italianidade", em Rhétorique de l'image, justifica-se pela necessidade de dar um nome aos estereótipos associados à Itália (BARTHES, 2002, p. 575). A distinção é feita para evitar uma confusão: se o texto utilizasse a palavra "Itália" para designar, ao mesmo tempo, o país e os estereótipos que o acompanham, ele estaria favorecendo a naturalização desses estereótipos, como se o significante "Itália" não pudesse ser pensado sem os significados mitológicos que o parasitam.

Contudo, o neologismo barthesiano extrapola os limites do uso "aceitável" das criações lexicais. O prefácio que ele escreveu para Physiologie du goût, do gastrônomo francês Brillat-Savarin, trata o assunto da seguinte maneira:

O neologismo (ou a palavra muito rara) é abundante em B. S. [BrillatSavarin], que ele usa sem freios, e cada uma de suas palavras inesperadas [...]

2 "L’auteur est réputé le père et le propriétaire de son œuvre ; la science littéraire nous apprend donc à respecter le manuscrit et les intentions déclarées de l'auteur". Tradução do autor. 
é a evidência de um prazer profundo, ligado ao desejo da língua: B. S. deseja a palavra como ele deseja as trufas, um omelete de atum, uma caldeirada; como todo neólogo, ele tem uma relação fetichista com a palavra isolada, circunscrita pela sua própria singularidade (BARTHES, 2002c, p. 816) ${ }^{3}$.

O neologismo, visto aqui como traço do desejo no texto, não é uma maneira de precisar um significado. Nem poderia ser diferente: para que o neologismo resultasse de uma preocupação exclusivamente onomasiológica, seria necessário que houvesse um desejo de estabilidade dos termos. Ora, a escritura é a inventividade da língua, sua capacidade de pluralizar-se. Assim, o Texto barthesiano não pode ser visto como uma sequência de signos fixos: ele possui uma vocação para o neologismo escritural, ou seja, para o sentido novo que, longe de velar pela constância da língua, desloca-a constantemente.

Some-se a isso o fato de "escritura" ter sido objeto de diversos neologismos. Evidentemente, o termo já existia em francês antes que Barthes o empregasse. Contudo, em seu primeiro livro, ele propôs uma definição nova da palavra (BARTHES, 2004)4. Essa é uma das definiçóes clássicas do neologismo: para o dicionário Houaiss, o neologismo pode ser uma "atribuição de novos sentidos a palavras já existentes na língua" (HOUAISS; VILLAR, 2007 p. 2009). Além disso, Barthes nunca se preocupou em manter essa expressão estável ao longo da obra. Ou seja, a palavra "escritura” não é apenas um termo usado para descrever os processos neológicos do Texto: ela é, ao mesmo tempo, resultado e agente desse processo.

Por isso, ao traduzir a palavra francesa écriture, Perrone-Moisés lançou mão de um processo que, como veremos, aproxima-se do neologismo. $\mathrm{O}$ português conta com dois termos para traduzir a expressão francesa: "escritura" e "escrita”. Como as duas palavras são quase sinônimas, elas não deveriam, a princípio, ser objeto de grandes debates. Contudo, em seu artigo de 1977, intitulado Escrita ou escritura?, Perrone-Moisés propóe uma solução particular (2012a). Ela sugere relativizar a sinonímia dessas palavras para ativar suas diferenças. Desse modo, "escritura” passará a significar toda escrita que faz dessa atividade um espetáculo: o escritor trabalha sua linguagem para que ela seja vista pelo leitor. A escritura é, então, uma atenção à língua que se torna propositalmente visível: o escritor não nos oferece apenas um ato de comunicação, mas também o prazer de uma linguagem trabalhada.

3 "Le néologisme (ou le mot très rare) abonde chez B.S; il en use sans frein, et chacun de ses mots inattendus [...] est la trace d'un plaisir profond, qui renvoie au désir de la langue : B. S. désire le mot, comme il désire des truffes, une omelette au thon, une matelote ; comme tout néologue, il a un rapport fétichiste au mot seul, cerné para sa singularité même.” Tradução do autor.

4 Para uma análise da primeira acepção barthesiana do termo, ver TENÓRIO DA MOTTA, 2010. 
Apesar de sua complexidade, não é "escritura” que aparece como enigmática nesse texto, pois o termo já havia sido extensamente estudado em Texto, crítica, escritura (PERRONE-MOISÉS, 2005). Isso porque, na época, o advento desse termo anunciava uma revolução na forma como víamos o texto. De fato, nos anos 70, "escrita" era uma expressão facilmente reconhecível porque incluía a quase totalidade da produção de textos até então. Todo texto escrito podia ser considerado, no limite, como uma escrita, pois seu objetivo era exprimir uma informação da maneira mais clara possível. Poderíamos, a princípio, objetar que a literatura, prática relativamente marginal, constituía uma exceção. Mas, até essa prática dava origem a uma escrita que negava seu caráter de escritura: ao "explicar" um texto, a crítica não está, na verdade, procurando extrair as informações que ele veicula? Assim, em última análise, toda obra literária possuía um conteúdo que era passível de ser transformado em uma linguagem mais compreensível. Daí as imagens da luz e da escuridão, que sempre permeiam o vocabulário crítico. O comentador "esclarece" o texto, ou seja, ilumina aquilo que, antes, era obscuro. O corolário desse procedimento é que haveria um tipo de linguagem que seria naturalmente mais clara do que uma outra, atribuindo ao estilo literário um trabalho de complexificação daquilo que poderia ser exprimido de maneira simples. Contudo, a escritura adquiriu um reconhecimento tal, sendo uma prática aceita até mesmo em documentos acadêmicos oficiais, como dissertaçóes de mestrado e teses de doutorado, que não podemos mais encarar a escrita com naturalidade. Assim, a ascensão da escritura provocou um questionamento sobre aquilo que era, até então, prática corrente nos textos intelectuais.

Vejamos como Perrone-Moisés descreve o termo "escrita": em primeiro lugar, ela aparece definida negativamente: escrita é tudo o que não é escritura. Se a escritura é "todo discurso em que as palavras náo são usadas como instrumento, mas encenadas, teatralizadas como significantes", podemos supor que a escrita é o discurso que usa as palavras como instrumento e que se preocupa com o significado em detrimento do significante. Em um segundo momento, "escrita" atua em um sistema de diferenças: opõe-se à "fala" e à "leitura", ao passo que "escritura" se opóe à "literatura" e "escrevência". Por fim, lemos que a escrita possui uma conotação "instrumental" (PERRONEMOISÉS, 2012a, p. 70). Talvez seja oportuno deter-se nessa última acepção do termo.

Nos estudos barthesianos, estamos acostumados a opor à escritura esse uso instrumental da língua que, no mais das vezes, é designado pela palavra "escrevência". De fato, "escrita" pode parecer, a princípio, como um simples sinônimo desse termo. Contudo, um dos traços mais importantes

5 Perrone-Moisés revisaria, mais tarde, as relaçôes entre "escritura" e "literatura" depois da publicaçáo da aula inaugural de Barthes no Collège de France (2012b). 
do pensamento barthesiano é a ubiquidade da linguagem: para ele, não há nada que esteja no exterior da língua. Ora, a noção de "instrumento" cria um problema de difícil resolução. De fato, o instrumento é um meio que utilizamos para atingir um determinado objetivo. Supóe-se, então, que a língua não produz o conteúdo de um texto, mas é apenas aquilo que o comunica. A língua serviria, assim, de simples veículo para a transmissão de algo que, por um lado, foi elaborado fora dela.

Com isso, não queremos dizer, evidentemente, que Barthes não tenha utilizado a palavra "escrevência" no sentido instrumental. A contradição é, sabemos, uma das marcas mais notáveis de seus textos. No entanto, ele tomou certas precauçóes que passaram desapercebidas para a maioria de seus leitores (PROCOPIO FERRAZ, 2019). Perrone-Moisés assinala que a escrevência pode verter-se em escritura. No seminário de 1973-1974, ao qual a autora assistiu, ela relata (advertindo, de passagem, que suas notas podem ser "infiéis" ao discurso de Barthes), que ele concebe uma escrita na qual se opera "a fusão do sapiencial com o existencial, do consciente com o inconsciente: ideias-palavras ou pensamentos-palavras, "palavras que têm o ar de pensar" (BARTHES apud PERRONE-MOISÉS, 2005, p. 36). Trata-se de uma escrita que já não está mais voltada para o significado, mas joga com os significantes: as "palavras que têm o ar de pensar" são termos que parecem ceder ao uso instrumental da língua, mas que, na verdade, são animadas por um impulso análogo ao da escritura. Isso quer dizer que o escritor parte das palavras e não dos conceitos que elas veiculam para estabelecer uma escritura que se esconde sob a aparência de uma escrevência. É um processo que toma a escrevência por álibi para poder circular tanto como trabalho da língua quanto como trabalho do pensamento, tal qual o morcego que se apresenta como rato ou como ave para fugir de seus predadores.

Por isso, cremos poder realizar uma pequena infidelidade com relaçáo ao texto de Perrone-Moisés ao tentar desenvolver as potencialidades dessa escrita híbrida. Procuraremos, aqui, desvincular a escrita da escrevência, atribuindo àquela o caráter produtivo que esta náo comporta. De fato, o próprio texto de Perrone-Moisés abre-nos essa possibilidade quando emprega a imagem do teatro. Como vimos, ela qualificou a escritura de "encenação", falando em uma "teatralização" da língua. Ora, essas imagens pressupóem uma ambiguidade. Como teatralização, a representação cênica é uma atividade que chama a atenção para sua própria linguagem: é o espetáculo que procura exibir sua própria artificialidade. Desse modo, a teatralização é o trabalho de demonstraçáo da arte; é o que faz com que seu público olhe atentamente para o cenário, para os atores ou para o roteiro: é uma função poética, já que aponta para a espessura da linguagem. 
A encenação é o teatro que busca esconder essa espessura: ela cria uma aparência de realidade, ou seja, provoca, no espectador, uma ilusão. A linguagem teatral busca, desse modo, produzir um efeito de transparência, como se ela pudesse desaparecer para dar lugar àquilo que representa. Mostramse, nesse caso, os personagens e não os atores, o lugar e não o cenário, a história e não o roteiro: há a intenção de fazer com que o teatro apareça como um lugar natural, evitando a espetacularização do significante. Evidentemente, sabemos que nenhum dos termos mencionados pode existir sem o outro: para que se consiga fazer aparecer os personagens, é necessário um trabalho de apagamento que não é menos intenso do que a tentativa de evidenciá-lo.

Podemos imaginar, entáo, a escrita como encenação, ou seja, como um ato de linguagem que se esconde enquanto tal. Ela se apresenta como um apagamento da linguagem para criar um efeito de clareza. Nesse sentido, ela é a aparência de uma transmissão de conteúdo. Isso não quer dizer, evidentemente, que a língua possa simplesmente comunicar uma mensagem: sabemos hoje que o sentido de um texto é indistinguível de sua formulação. $\mathrm{Na}$ verdade, toda a escrita carrega com ela a história de um trabalho linguístico. A escrita não é, portanto, menos artificial do que a escritura; na verdade, toda sua arte consiste em fabricar sua própria naturalidade, trabalhando para seu desaparecimento.

Neologismos? Uma questão de fidelidade

No colóquio A circulação de paradigmas críticos em Íbero América, realizado em 2018 na USP, em São Paulo, apresentei a comunicação Apropriaçôes e transformaçóes na escrita de Leyla Perrone-Moisés, e expus a ideia de que esse gesto de Perrone-Moisés que estudamos aqui, ou seja, a distinção entre "escrita" e "escritura", que dota de sentidos novos palavras que, antes, eram consideradas sinônimas, era um tipo de neologismo. Perrone-Moisés, que estava presente no evento, levantou uma objeção. De fato, em seu artigo, há uma atenção para as raízes dos termos "escrita" e "escritura", além de seu emprego na história da língua portuguesa. Ela explica que recebeu uma carta de Segismundo Spina, atestando que dois termos em latim, scriptum e scriptura, possuíam sentidos similares, mas que o segundo termo era de uso mais amplo, podendo significar "obra literária" ou "obra de estilo". Além disso, o termo scriptura possui uma característica particularmente interessante: ele é a forma substantiva do particípio futuro ativo do verbo scribere. Scriptura pode ser entendido, então, como aquilo que se há de escrever (PERRONE-MOISÉS, 2012a, p. 72). Ora, sabemos que, para Barthes, écriture está tensionada em direçâo ao futuro, pois ela é produção de novos sentidos. Como lembra Perrone-Moisés, écriture é "um novo profetismo" (BARTHES, apud PERRONE-MOISÉS, 2012a, p. 72). Ela cita também empregos de "escritura” em Camóes, Vieira, 
Mario de Andrade e Clarice Lispector (PERRONE-MOISÉS, p. 72-73). Como falar, então, em neologismo, se o uso da palavra é mais antigo do que a própria língua portuguesa?

Evidentemente, inclinei-me diante dessas objeçóes, admitindo que o uso do termo "neologismo" poderia parecer inadequado. Por outro lado, sustentei que não é possível dizer que o texto de Perrone-Moisés não produz novos sentidos. Esse emprego particular dos termos é inédito na crítica barthesiana. A autora assinala, por exemplo, que os portugueses preferem utilizar apenas "escrita", ignorando a distinção (PERRONE-MOISÉS, 2012a, p. 71). Em todo caso, a diferenciação não é naturalmente perceptível: para os leitores lusófonos, ela só passou a existir quando o texto da autora a produziu. Coloquei-me, então, em uma situação próxima daquela que estamos descrevendo neste artigo: partindo de uma posição de absoluta fidelidade ao texto, afastei-me dele, traindo suas intençôes.

Passei a refletir, então, sobre um modo de dar conta dessa questão. Analía Gerbaudo, presente no evento, aconselhou-me a substituir o termo "neologismo" por "paleologismo". A palavra foi proposta, em francês, em um artigo intitulado Terminologie de la néologie: lacunes, flotements et trop-pleins (SABLAYROLLES, 2006). Nesse texto, Jean-François Sablayrolles, que estuda as diversas formas pelas quais novas palavras podem aparecer em uma língua, procura corrigir determinados problemas terminológicos em seu campo. Ele tenta, na medida do possível, fazer com que um termo corresponda a apenas um conceito. $\mathrm{O}$ autor embrenha-se, entáo, na multitude de expressóes que foram usadas para descrever os diferentes modos de formação de neologismos, como "morfemicidade", "compocamento" ou "deflexivação" (SABLAYROLLES, 2006, p. 85-86), dando-nos, de passagem, a impressão de que a neologia só pode ser compreendida a partir dos processos que ela mesma criou. Por exemplo, "compocamento" descreve a junção de palavras que não possuíam, em sua origem, similaridades morfológicas que justificassem essa junção. Ora, esse termo é, ele mesmo, um fruto do processo que descreve, pois ele é formado a partir de "composição" e "truncamento", termos com estruturas morfológicas bastante distintas. Tem-se a impressão, desse modo, que a linguagem corrente carece dos meios para pensar suas próprias mutações.

Ao final de seu texto, Sablayrolles escreve sobre um curioso paradoxo: a tentativa de certos autores de incorporar o arcaísmo ao neologismo. Para esses autores, uma palavra antiga, quando introduzida em um discurso moderno, produz um efeito de novidade, já que o leitor, muitas vezes, não a conhece. Esse procedimento provoca um esforço de reconstituiçáo do significado a partir da morfologia e do contexto no qual ele é empregado. Ora, esse é o esforço que deve ser feito para qualquer tipo de neologismo, o que justifica a sua incorporação ao estudo da neologia. Esse argumento é próximo daquilo que 
sustentamos no colóquio: a maneira pela qual Perrone-Moisés usa "escritura", apesar da antiguidade de seu emprego, pode ser considerada nova pelo leitor.

Contudo, essa ideia parece, para Sablayrolles, intolerável, pois significa que "arcaísmo", pode, a depender do autor consultado, ser tratado como antônimo de "neologismo" ou como uma de suas categorias. Produz-se um paradoxo que coloca em curto-circuito toda a tipologia proposta. Para solucionar o problema, ele propóe "paleologismo", que serve para descrever o efeito de novidade causado pela introduçáo de termos antigos. Um paleologismo é a reintrodução de uma palavra desconhecida pela maioria dos leitores modernos. O paleologismo pode, então, distinguir-se do arcaísmo. Para ser considerada um arcaísmo, a palavra precisa, ao mesmo tempo, ser compreendida pelos leitores contemporâneos e não ser mais empregada por eles. Ela é, assim, o uso de um termo antiquado que ainda é conhecido pelo leitor. Podemos pensar, por exemplo, em certas gírias antigas, que já saíram de moda, mas que, por uma razão ou por outra, ainda são conhecidas da maioria dos locutores de uma língua (SABLAYROLLES, 2006, p. 87-88).

Mais tarde, encontraremos novas precisóes sobre a definição de "paleologismo". Sablayrolles afirma que o conceito pode ser usado, também, para descrever a reativação de sentidos etimológicos em termos correntes (2007, p.7). De fato, esse uso pede do leitor o mesmo esforço que um neologismo tradicional. Trata-se de um gesto que encontramos com frequência em Barthes: ao se dizer anarquista, ele não está se referindo ao movimento político habitualmente designado por esse nome, mas antes a sua atitude de se colocar contra o arkhé, ou seja, o poder. $\mathrm{O}$ an-arquismo de Barthes pode ser definido, desse modo, como uma oposiçáo a todas as formas de poder. A palavra testa tanto nossos conhecimentos etimológicos quanto nossa capacidade de inferir o sentido a partir de seu contexto (BARTHES, 2002d, p. 436). Esse é o processo utilizado por Perrone-Moisés para estabelecer o sentido de "escritura".

Assim, podemos afirmar que o tipo particular de neologismo de PerroneMoisés se situa exatamente na fronteira entre a fidelidade e a infidelidade. De fato, como poderíamos recusar aos leitores de Barthes o recurso ao neologismo 
se o próprio texto barthesiano dele faz um uso irrestrito? Como ser fiel aos sentidos já produzidos quando a vocação do neologismo é a inovação? Só é possível ler Barthes mantendo-nos em um equilíbrio instável entre o rigor e a invençáo, escrevendo um texto novo ao mesmo tempo em que procuramos nos ater àquilo que já foi escrito. Essa ambiguidade está plenamente realizada na distinção entre "escrita" e "escritura". Efetivamente, essa distinção não distorce a noção original: Perrone-Moisés assinala sentidos que estão realmente presentes no texto barthesiano. Contudo, algo de novo foi criado, que não poderia ter sido compreendido sem o duplo gesto da autora que, a partir de sua atividade como crítica e como tradutora, permite o advento de novas interrogaçóes.

\section{Referências}

BARTHES, Roland. Rhétorique de l'image. In: Euvres complètes, t. II. Paris: Seuil, 2002, p. 573-588.

BARTHES, Roland. L'ancienne rhétorique: aide-mémoire. In: Euvres complètes, t. III. Paris: Seuil, 2002a, p. 527-601.

BARTHES, Roland. De l'œuvre au texte. In: Euvres complètes, t. III. Paris: Seuil, 2002b, p. 908-916.

BARTHES, Roland. Lecture de Brillat-Savarin. In: Euvres complètes, t. IV. Paris: Seuil, 2002c, p. 808-826.

BARTHES, Roland. Leçon. In: Euvres complètes, t. V. Paris: Seuil, 2002d, p. 427-446.

BARTHES, Roland. O grau zero da escrita. São Paulo: Martins Fontes, 2004.

HOUAISS, Antonio; VILLAR, Mauro de Salles. Dicionário Houaiss de lingua portuguesa, 2a impressão com modificações. Rio de Janeiro: Objetiva, 2007.

OUSTINOFF, Michaël. La traduction, sixième édition. Paris: PUF ; Humensis, 2018, ed. Kindle.

PERRONE-MOISÉS, Leyla. Texto, critica, escritura, 3a. ed. São Paulo: Martins Fontes, 2005.

PERRONE-MOISÉS, Leyla. Roland Barthes, o infiel. In: Com Roland Barthes. São Paulo: Martins Fontes, 2012, p. 23-27.

PERRONE-MOISÉS, Leyla. Escrita ou escritura? In: Com Roland Barthes. São Paulo: Martins Fontes, 2012a, p. 69-74.

PERRONE-MOISÉS, Leyla. Deslocamentos da noção de escritura. In: Com Roland Barthes. São Paulo: Martins Fontes, 2012b, p. 75-89. 
PERRONE-MOISÉS, Leyla. Relembrando Barthes, sem autópsias acadêmicas. In: Com Roland Barthes. São Paulo: Martins Fontes, 2012c, p. 123-131.

PERRONE-MOISÉS, Leyla. De volta a Roland Barthes. In: Com Roland Barthes. São Paulo: Martins Fontes, 2012d, p. 132-136.

PROCOPIO FERRAZ, Paulo. O avesso das frases: metalinguagem, palinódia e epanortose em Roland Barthes. In: AMIGO PINO, Claudia et al. (org). Novamente Roland Barthes. Natal: IFRN, 2018, p. 181-196. Disponível em: https://memoria. ifrn.edu.br/handle/1044/1660. Acesso em: 20 nov. 2020.

PROCOPIO FERRAZ, Paulo. Escritores e escreventes: uma distinção política. Letras Raras, v. 8, n. 4, 2019, p. 84-92. Disponível em: [http://revistas.ufcg.edu.br/ch/ index.php/RLR/article/view/1638]. Acesso em: 7 jul. 2020.

SABLAYROLLES, Jean-François. Terminologie de la néologie : lacunes, flottements et trop-pleins. Sintaxe et sémantique, v. 1, n. 7, 2006, p. 79-80. Disponível em: [https://www.cairn.info/revue-syntaxe-et-semantique-2006-1-page-79.htm]. Acesso em: 12 maio 2020.

SABLAYROLLES, Jean-François. Archaïsme: un concept mal défini et des utilisations littéraires contrastées. Colloque "Stylistique de l'archaïsme". Cérisy, sept. 2007. Disponível em: [https://halshs.archives-ouvertes.fr/halshs-00735659]. Acesso em : 12 maio 2020.

TENÓRIO DA MOTTA, Leda. Roland Barthes e seus primeiros toques de delicadeza minimalista; sobre $O$ grau zero da escritura. Alea: estudos neolatinos, v. 12, n. 2, july/dec. 2010. Disponível em: [https://www.scielo.br/scielo.php?script=sci arttext\&pid=S1517-106X2010000200004]. Acesso em: 15 maio 2020.

Paulo Procopio Ferraz. Doutor pela Universidade Paris 8. Atualmente, desenvolve um pós doutorado em literatura francesa na Universidade de São Paulo sobre Roland Barthes, com o apoio da FAPESP. Estuda a crítica literária francesa do século XX e as maneiras pelas quais um texto crítico pode constituir-se como uma escritura, para além de seu papel de compreensão de uma obra literária.

E-mail: ppaferraz@gmail.com 